\title{
The Use of GPS to Validate NWP Systems: The HIRLAM Model
}

\author{
L. Cucurull \\ Institut d'Estudis Espacials de Catalunya, Barcelona, Spain \\ B. NAVASCUES \\ Instituto Nacional de Meteorología, Madrid, Spain \\ G. RUFFINI \\ Institut d'Estudis Espacials de Catalunya, Barcelona, Spain

\section{P. ElóSEgui} \\ Institut d'Estudis Espacials de Catalunya, Barcelona, Spain, and \\ Harvard-Smithsonian Center for Astrophysics, Cambridge, Massachusetts
}

\section{A. RIUS AND J. VILÀ}

Institut d'Estudis Espacials de Catalunya, Barcelona, Spain

(Manuscript received 8 July 1999, in final form 29 July 1999)

\section{ABSTRACT}

\begin{abstract}
A meteorological synoptic situation using Global Positioning System (GPS) observations and a numerical weather prediction (NWP) model in the vicinity of the Madrid Sierra, Spain, between 2 and 15 December 1996 has been studied. The experiment was characterized by high precipitable water (PW) values associated to rainfall events. The PW was estimated at the level of $1 \mathrm{~mm}$ with five GPS receivers to study the passage of a winter frontal system. The GPS network had baselines ranging from 5 to $50 \mathrm{~km}$. These observations have been used to study the spatial and temporal variations of PW.

For this same location and time period, PW calculations were carried out by HIRLAM (High-Resolution Limited Area Modeling), the hydrostatic NWP system operational at the Spanish National Weather Service. HIRLAM has been run in two modes: analysis (HIRLAM/A) and forecast (HIRLAM/F).

The comparison of PW values obtained using GPS and high-resolution HIRLAM/A shows a PW bias of $-0.4 \mathrm{~mm}$ (GPS-derived PW higher), and a root-mean-square (rms) difference of $2 \mathrm{~mm}$ (relative agreement of 85\%), which is in agreement with the standard deviation of each method. A similar comparison between GPS and the high-resolution HIRLAM/F results in a bias and rms that increase when extending the forecast range up to a bias of $-1.2 \mathrm{~mm}$ and an rms of $3 \mathrm{~mm}$ (relative agreement of $78 \%$ ) for the longest forecast range studied, which is $24 \mathrm{~h}$.

Radiosonde profiles from a location near one of the sites of the GPS network have also been used to estimate $\mathrm{PW}$. The PW bias and rms that result from comparing this data to the previous two methods are -1 and 1.6 $\mathrm{mm}$ (relative agreement of $88 \%$ ) between GPS and radiosondes, and -1.2 and $1.3 \mathrm{~mm}$ (relative agreement of $90 \%$ ) between radiosonde and HIRLAM/A.

The PW estimated from GPS is probed to be an accurate measurement to validate NWP models. The study also shows that GPS measurements can detect small-scale fluctuations and therefore can be used to evaluate NWP models with finer resolution.
\end{abstract}

\section{Introduction}

The water vapor distribution and content are critical parameters for the description of the state and evolution

Corresponding author address: Dr. Lidia Cucurull, Institut d'Estudis Espacials de Catalunya, Edif. Nexus-204, Gran Capita 2-4, 08034 Barcelona, Spain.

E-mail: cucurull@ieec.fcr.es of many physical processes in the earth's atmosphere. Although water vapor constitutes only a small fraction of all the atmospheric gases (fractional volume mixing ratio between 0.00001 and $0.01 \mathrm{ppm}$ ), its importance is far greater than this measure would indicate. For example, water vapor plays an important role in atmospheric processes that range, in spatial scales, from micro- to global meteorology. In addition, water vapor is a greenhouse gas and long-term variations in its total 
global content could potentially be used as an indicator of global climate change (Yuan et al. 1993). However, the distribution of water vapor is a highly variable function of both time and space and correlates poorly with surface humidity measurements. Lack of precise and continuous water vapor data is one of the major error sources in short-term forecasts of precipitation (Kuo et al. 1993, 1996). Although ground-based techniques such as radiosondes or water vapor radiometers (WVRs) are sensitive to the water vapor content present in the atmosphere, they can be expensive to operate and they provide either poor temporal resolution, poor spatial coverage, or both. (Radiosondes are launched typically only once every $12 \mathrm{~h}$, and they are sparse over wide areas in the globe; in contrast to space-based WVR, ground-based WVR have good temporal resolution but poor spatial coverage.) New observational techniques that are sensitive to the spatial and temporal distribution of the water vapor content in the atmosphere now have made possible the retrieval of precise and continuous estimates of water vapor with high spatial density. This is the case of the Global Positioning System (GPS). Even though GPS was originally designed for military navigation and positioning, the applications of this technique already abound in areas such as geodesy, volcanology, oceanography, or glaciology to cite a few. See, for example, Segall and Davis (1997), and references therein, for a review of some GPS applications for geodynamics and seismology.

The GPS constellation consists of 24 operational satellites (orbiting at an altitude of about $20000 \mathrm{~km}$ ) that transmit ranging data at two frequencies (1.2 and 1.6 $\mathrm{GHz}$ ). The GPS signal, as it propagates through the atmosphere, experiences an extra delay relative to the straight line where the atmosphere is replaced by vacuum. This extra delay, known as atmospheric delay, is commonly regarded as a nuisance parameter. However, due to the inherent sensitivity of the GPS system, this error source can be converted into the object of study. The use of GPS for the determination of water vapor content in the zenith direction with a precision of a few millimeters is a well-established technique (e.g., Bevis et al. 1992; Rocken et al. 1993, 1995; Businger et al. 1996; Duan et al. 1996).

Some of the atmospheric estimates obtained with GPS have been compared with estimates obtained with other techniques that are also sensitive to the amount of water vapor in the atmosphere, such as very-long baseline interferometry (VLBI) and WVR. Carlsson et al. (1996), for example, showed that the root-mean-square (rms) agreement between the water vapor delay estimates from these techniques is better than $10 \mathrm{~mm}$, though the VLBI estimates presented an unresolved systematic bias of about $5 \mathrm{~mm}$ compared to the other two methods. See section 2 for a discussion on the equivalence between water vapor delay (commonly known as wet delay) and precipitable water $(\mathrm{PW})$. The measurements from these three techniques, in turn, have been compared with in- tegrated values of water vapor obtained with radiosondes, which measures the in situ state of the atmosphere. For example, the agreement found between estimates of PW obtained using GPS and radiosondes is at the 2-mm rms level (Rocken et al. 1993, 1995; Duan et al. 1996; Tregoning et al. 1998; Emardson et al. 1998).

One of the most suitable atmospheric application of GPS is perhaps the assimilation of water vapor content estimates into numerical weather prediction (NWP) and climate models. The HIRLAM (High-Resolution Limited Area Modeling) NWP model (Källen 1996) is a short-range weather forecasting system over a limited area. The lack of humidity measurements that could potentially be assimilated into NWP forecast models is the main reason of its (sometimes) low reliability (Kuo et al. 1993, 1996). The fact that GPS can supply these data in near-real time (Rocken et al. 1997) and at low cost is changing, at the algorithmic level, the way these models are being used to assimilate the GPS estimates (Zou et al. 1996; Kuo et al. 1996). GPS slant delay measurements (Ware et al. 1997), the delay along the lines of sight from the receiver to the satellites (as opposed to zenith delays, the delay in the zenith direction), provide information that can be used to extract vertical profiles of the index of refraction of the atmosphere. These data will possibly be assimilated into NWP models in the future in a variational assimilation context. In preparation for these efforts, it is necessary to determine how NWP models will fare in simulating GPS slant delay measurements. In this study we have concentrated on estimates of PW derived from zenith delay measurements acquired at several ground-based GPS sites. The results from this study will provide an upper bound on the size of the GPS errors that are acceptable so that these GPS-derived PW estimates have a positive impact on numerical weather prediction models once they are correctly assimilated.

Yang et al. (1999) have studied the ability of the HIRLAM model to reproduce the spatial and temporal evolution of PW by comparing the model values with GPS estimates obtained on a spatial scale of 100-1500 $\mathrm{km}$ in northern Europe. Our goal here is to perform a comparative study of the spatial and temporal distribution of the water vapor content as obtained with GPS and modeled with HIRLAM on a smaller scale (5-50 $\mathrm{km}$ ) and high topographic relief. Data from radiosonde launches were also available in the area of study and have been used as an additional check. The geographical region selected for the experiment, the Madrid Sierra, Spain, is characterized by complex topography. The GPS-derived PW data will be used to check the reliability of the model performance in an area with highly varied topography.

Section 2 reviews the propagation effects on GPS electromagnetic waves traveling through the neutral atmosphere, and how the atmospheric water vapor content can be determined through the modeling of these effects. The experimental setup and the analysis of the datasets 
used in this study are described in section 3. Section 4 analyses the different datasets treated in this study. We finally present and discuss the results of this comparative study in section 5. Particular emphasis will be devoted to the study of one of the two frontal systems that crossed the network during the experiment.

\section{Modeling of the neutral atmospheric delay}

The (electrically) neutral atmosphere affects the propagation of electromagnetic signals by retarding and bending them. These effects can be determined if one knows the index of refraction $n$, or, more conveniently, the refractivity $N$, defined as $10^{6}(n-1)$. If we neglect the contribution of the liquid water content, the total refractivity of the neutral atmosphere is given by (Smith and Weintraub 1953; Thompson et al. 1986)

$$
N=k_{1}\left(\frac{P_{d}}{T}\right) Z_{d}^{-1}+k_{2}\left(\frac{P_{w}}{T}\right) Z_{w}^{-1}+k_{3}\left(\frac{P_{w}}{T^{2}}\right) Z_{w}^{-1},
$$

where $P_{d}$ and $P_{w}$ are the partial pressures (in $\mathrm{hPa}$ ) of dry air and water vapor, respectively; $T$ is the temperature (in K) of the atmosphere; $k_{1}=(77.604 \pm 0.014)$ $\mathrm{K} \mathrm{hPa}^{-1} ; k_{2}=(64.79 \pm 0.08) \mathrm{K} \mathrm{hPa}^{-1} ; k_{3}=(3.776$ $\pm 0.004) \times 10^{5} \mathrm{~K}^{2} \mathrm{hPa}^{-1}$ are the refractivity constants (Thayer 1974); and $Z_{d}^{-1}$ and $Z_{w}^{-1}$ are the inverse compressibility factors of the dry gases and water vapor (Owens 1967), respectively. For an ideal gas $Z=1$, and for the atmosphere differs from unity by a few parts per thousand.

The atmospheric delay is the integral of the refractivity along the ray path. It is useful to separate the zenith atmospheric delay as the sum of two terms (Davis et al. 1985): the hydrostatic delay and the wet delay. These two delay terms are given by the expressions

$$
\begin{aligned}
\Delta L_{h}^{z} & =\int_{0}^{\infty} d z N_{h} \\
& =\int_{0}^{\infty} d z\left(k_{1} \frac{P_{d}}{T} Z_{d}^{-1}+\left(k_{2}-k_{2}^{\prime}\right) \frac{P_{w}}{T} Z_{w}^{-1}\right) \text { and } \\
\Delta L_{w}^{z} & =\int_{0}^{\infty} d z N_{w}=\int_{0}^{\infty} d z\left(k_{2}^{\prime} \frac{P_{w}}{T} Z_{w}^{-1}+k_{3} \frac{P_{w}}{T^{2}} Z_{w}^{-1}\right),
\end{aligned}
$$

where $h$ refers to hydrostatic, $w$ to wet, $z$ is the zenith direction; $k_{2}^{\prime}=k_{2}-k_{1}\left(M_{w} / M_{d}\right) \approx 17 \pm 10 \mathrm{~K} \mathrm{hPa}^{-1}$; and $M_{w}$ and $M_{d}$ are the molar weights of water vapor and dry gases, respectively. Hence, $\Delta L^{z}=\Delta L_{h}^{z}+$ $\Delta L_{w}^{z}$. The zenith hydrostatic delay is a result of the induced dipole moment and has a typical value of around $2300 \mathrm{~mm}$ at sea level. The zenith wet delay, which is associated with the atmospheric water vapor, has a nominal value of about $100 \mathrm{~mm}$ at sea level, and it is due to the permanent dipole moment of precipitable water vapor and liquid water present in the troposphere. The contribution of liquid water to total precipitable water is mostly smaller than $1 \%$. The wet contribution is very difficult to model because it is highly variable in space and time.

The zenith hydrostatic delay can be accurately modeled if measurements of total surface pressure are available (Saastamoinen 1972):

$$
\Delta L_{h}^{z}=(2.2779 \pm 0.0024) \frac{P_{0}}{f(\lambda, H)}
$$

where $\Delta L_{h}^{z}$ is expressed in millimeters, $P_{0}$ is the surface pressure expressed in hectopascals and $f(\lambda, H)=1-$ $0.00266 \cos (2 \lambda)-0.00028 H$ accounts for the variation in gravitational acceleration with latitude $\lambda$ and the height $H$ of the surface above the geoid (in $\mathrm{km}$ ). This delay can be predicted to better than a millimeter with surface pressure accuracies of $0.4 \mathrm{hPa}$ (see, e.g., Elgered et al. 1991 for a discussion on the uncertainty associated to the zenith hydrostatic delay).

The methods used to obtain estimates of zenith wet delay from geodetic techniques and their comparison with a numerical weather prediction model are the subjects of the following sections. Once estimated, the zenith wet delays can be accurately converted into PW by using the expression (Bevis et al. 1994)

$$
\mathrm{PW} \equiv \Delta L_{w}^{z} \Pi\left(T_{m}, \rho_{v}\right),
$$

where PW and $\Delta L_{w}^{z}$ are expressed in millimeters and $\Pi\left(T_{m}, \rho_{v}\right)$ is given by

$$
\Pi=\frac{10^{6}}{\rho_{v} R_{v}\left[\left(k_{3} / T_{m}\right)+k_{2}^{\prime}\right]} .
$$

In (6), $R_{v}$ is the specific gas constant for water vapor (461.5 $\left.\mathrm{J} \mathrm{kg}^{-1} \mathrm{~K}^{-1}\right) ; T_{m}$ is the mean temperature of the atmosphere, defined as $T_{m}=\left(\int_{0}^{\infty} d z P_{w} / T\right) /\left(\int_{0}^{\infty} d z P_{w} / T^{2}\right)$ (Davis et al. 1985); and $\rho_{v}$ is the density of liquid water. The mean temperature depends on the vertical profile of $P_{w}$ and atmospheric temperature. Fortunately, the mean temperature has been empirically found to be well correlated with surface temperature (Bevis et al. 1992). For example, based on more than 120000 radiosonde profiles from 38 sites in Europe, Emardson and Derks (1999) determined a value of $\Pi \sim 0.15$ for a timeaveraged ground temperature of $275 \mathrm{~K}$ with a relative rms error of $1.14 \%$. Because this error is significantly smaller than the error of the estimates of zenith wet delays, an error of $10 \mathrm{~mm}$ in zenith wet delay propagates to $1.5 \mathrm{~mm}$ in PW after (6). It is now possible to recover PW routinely from GPS data with an rms error of less than $2 \mathrm{~mm}+1 \%$ of the PW and a long-term bias of less than $2 \mathrm{~mm}$ (Dixon et al. 1990; Herring et al. 1990; Bevis et al. 1992; Rocken et al. 1997; Ware et al. 1997).

We use mapping functions to relate atmospheric delays as measured in any sky direction to zenith delays. See Niell (1996) for a review and error discussion on the various mapping functions employed in geodetic analysis that do not incorporate azimuthal variation, and Chen and Herring (1997) for mapping functions that do incorporate azimuthal asymmetry. 


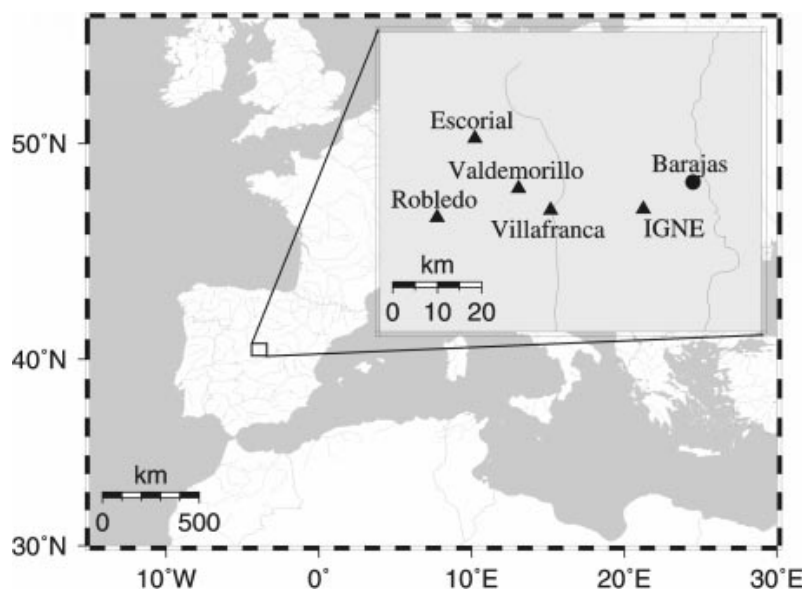

FIG. 1. Geographical location of the GPS (triangles) and radiosonde (circle) sites involved in the experiment. The geoid altitude of the sites is as follows: Barajas (633 m), Escorial (1026 m), IGNE (715 m), Robledo (777 m), Valdemorillo (794 m), and Villafranca (596 $\mathrm{m})$.

\section{Experimental setup and meteorological situation}

We conducted a GPS experiment during 2-15 December 1996 in the Madrid Sierra of Spain to 1) study the spatial and temporal variations of PW and 2) compare the GPS-derived estimates of PW with PW values simulated with the HIRLAM numerical weather prediction model.

The GPS network consisted of five Trimble 400SSE receivers forming baselines ranging in length from 5 to $50 \mathrm{~km}$. Figure 1 shows the geographical location of the GPS sites. We employed Trimble geodetic L1/L2 antennas with ground plane (Elósegui et al. 1998). The geographical region selected for the experiment is characterized by complex topography with maximum altitude difference between GPS sites of about $400 \mathrm{~m}$. Figure 2 shows a contour plot of the topography of the region. Meteorological data were collected at one of the sites (Robledo) during the experiment. As part of the meteorological package, Robledo operates a high-precision $(\sim 0.3 \mathrm{hPa})$ barometer. Vertical profiles of temperature, pressure, and relative humidity were also available from 12-hourly radiosonde launches at the Barajas airport.

Two frontal systems crossed the GPS sites during the experiment-the first at around 4-6 December and the second at around 12-14 December. We selected the second front to perform a more detailed analysis of GPSderived PW because this presented the largest PW values. The synoptic regime corresponding to this frontal passage can be observed in the 36-h sequence of Fig. 3. Each map shows a temporal snapshot of the analyzed mean sea level pressure and temperature at $850 \mathrm{hPa}$ pressure-altitude, as determined by the HIRLAM/A low-resolution $\left(0.5^{\circ} \times 0.5^{\circ}\right)$ model. A low pressure system seen in the North Atlantic (somewhat to the northwest of the Iberia Peninsula) at 1200 UTC 12 December

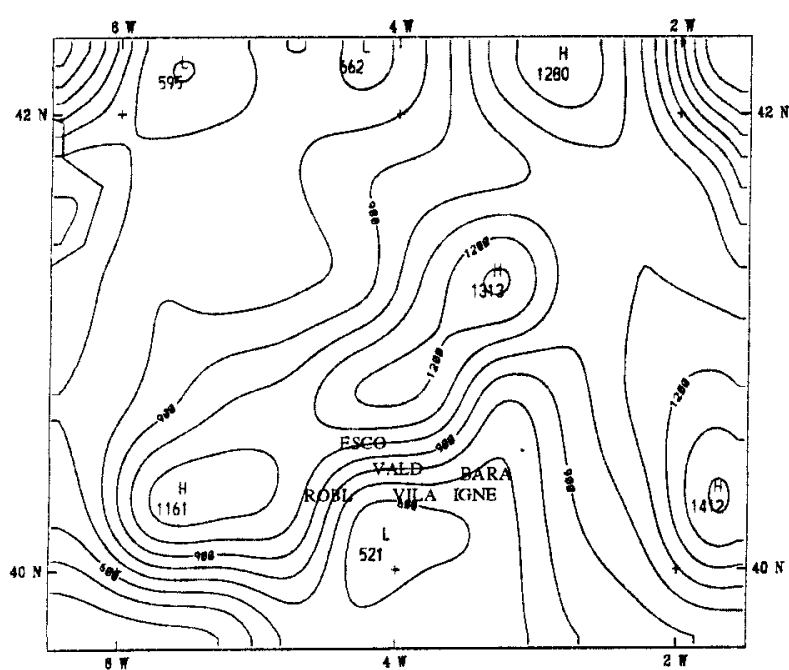

FIG. 2. Contour plot of the topography of the region and the location of the five GPS stations. Altitude is in meters above sea level. (BARA: Barajas, ESCO: Escorial, ROBL: Robledo, VALD: Valdemorillo, VILA: Villafranca.)

moves east reaching the continent and overpassing the area of interest during 13 December. This low pressure system advected warm, moist air from the southwest as it approached the coast. The front brought steady precipitation to the area of the experiment, with heaviest rain at around the end of 12 December. Figure $3 \mathrm{c}$ shows that the flow is changing from southwesterly to northwesterly in the center of the Iberia Peninsula on 14 December.

\section{Data analysis and simulations}

\section{a. GPS analysis}

The GPS observations at each site consisted of data streams, simultaneously received from six to eight satellites, of undifferenced dual-frequency carrier-phase and pseudorange measurements obtained every $30 \mathrm{~s}$. We used GPS satellite precise orbits and clocks as well as consistent earth-rotation parameters provided by the International GPS Service (IGS), together with the GIPSY/OASIS-II (version 4) software package (Webb and Zumberge 1993 and references therein) to estimate zenith total delays at the five GPS sites with a precision of about $0.5 \mathrm{~cm}$ (Elósegui et al. 1998). This software uses a stochastic filter to provide time-dependent estimates of the atmospheric delays for each site. The dynamics of these delays were modeled as a random-walk stochastic process, with a drift rate of $0.25 \mathrm{~cm} \mathrm{~h}^{-1 / 2}$. This drift rate was chosen to be consistent with measurements obtained with a collocated WVR (see Elósegui et al. 1998 and Ruffini et al. 1999 for a more thorough discussion).

To derive precipitable water from the estimates of zenith total delay we first calculated and subtracted the hydrostatic contribution. We used pressure values at 


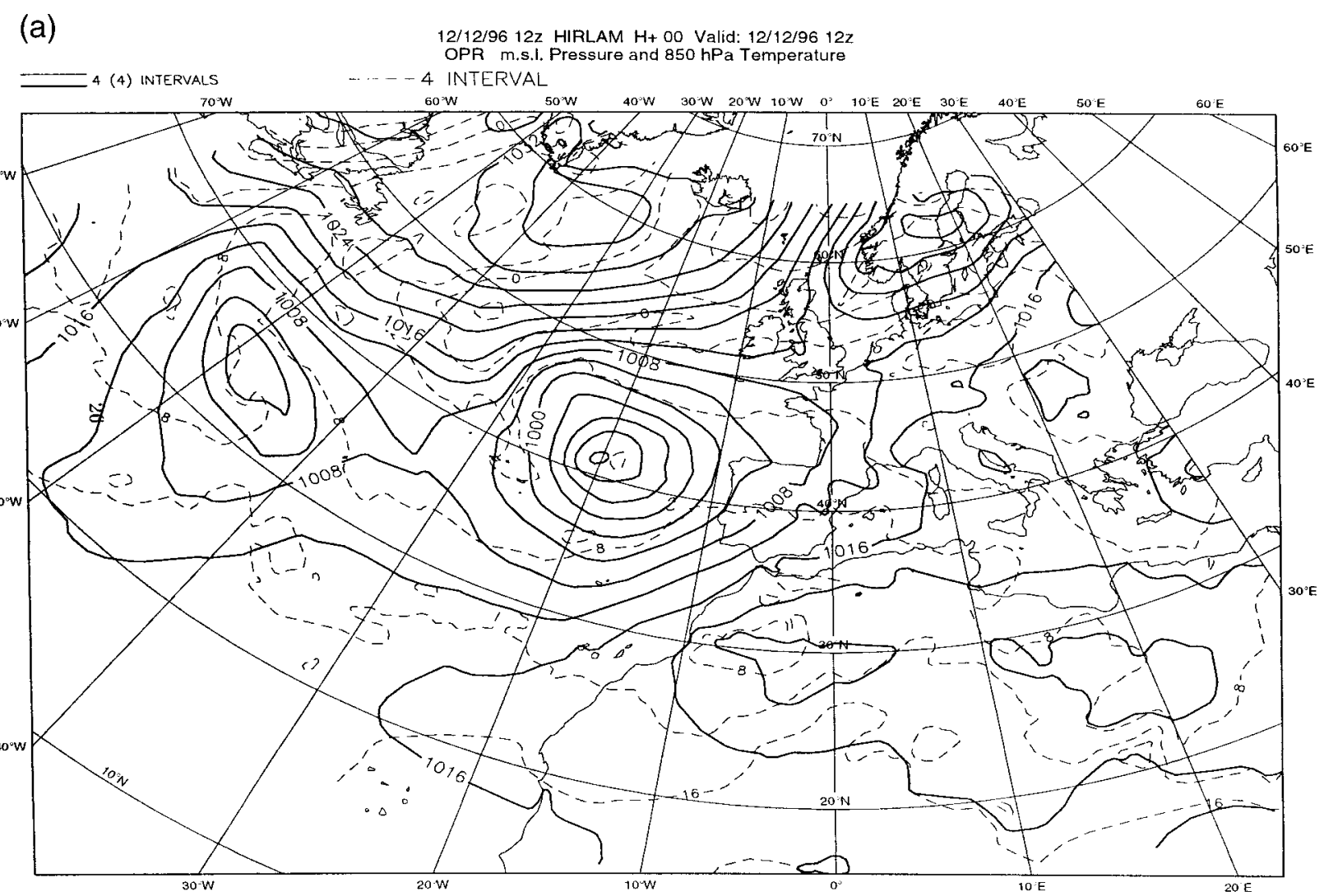

FIG. 3. Low-resolution, HIRLAM/A maps of low level atmospheric flow for (a) 1200 UTC 12 Dec, (b) 1200 UTC 13 Dec, and (c) 0000 UTC 14 Dec. The contours represent mean sea level pressure (solid) and temperature at $850 \mathrm{hPa}$ (dashed).

each site to compute zenith hydrostatic delays via (4). In the absence of surface pressure measurements at all sites but Robledo, we have used HIRLAM/A to calculate 6-hourly pressure values. The required pressure measurements between these modeled values we filled up using the pressure data collected at Robledo corrected for height differences between sites. This is justified because of the small bias $(0.4 \mathrm{hPa})$ between the readings of the barometer and the surface pressure values calculated by the NWP model at the Robledo site over the course of the whole experiment. This small bias will account for the 1-mm bias of the zenith hydrostatic delay. Verification scores of both HIRLAM analysis and forecasts against observations were produced routinely during the objective verification procedure at the Instituto Nacional de Meteorologia (INM). The pressure rms error of HIRLAM/A at mean sea level is $1.5 \mathrm{hPa}$. We have therefore adopted this value as the expected error of the estimates of surface pressures at the other GPS sites, which is equivalent to $3.4 \mathrm{~mm}$ error in terms of zenith hydrostatic delays. The resulting uncertainty of the zenith wet delays estimates is about 6 $\mathrm{mm}$ (the errors in the zenith total delay and the hydrostatic delay added in quadrature) or, equivalently, about $1 \mathrm{~mm}$ PW.

Precipitable water estimates for the whole campaign (taken every 150 s) are shown in Fig. 4 for all five GPS sites. The time series for all the stations of the network are quite similar, though small differences between stations due to short-term water vapor variations can be observed. It is particularly important to determine how sensitive are the GPS data to specific meteorological situations. For this reason, we have selected the front passage of 12-14 December described above, which will be studied in greater detail in the following section. Table 1 shows the average and rms PW values for this front as well as for the first front and the entire campaign. From the table, it is clear the influence of orography on the measurements. This dependence is basically due to a scaling of the amount of integrated water vapor with altitude. In order to carry out a proper intercomparison of the data it would be necessary to correct for this height-dependent scaling factor. However, we have not found any empirical function (e.g., an exponential law) that could model adequately this dependence, perhaps due to the complex topography of the network and/or the highly unstable atmospheric conditions during the experiment. The table reveals a significant increase of PW due the passage of the second front. Also, the rms values for the entire campaign are larger than those of the two fronts because the data span 


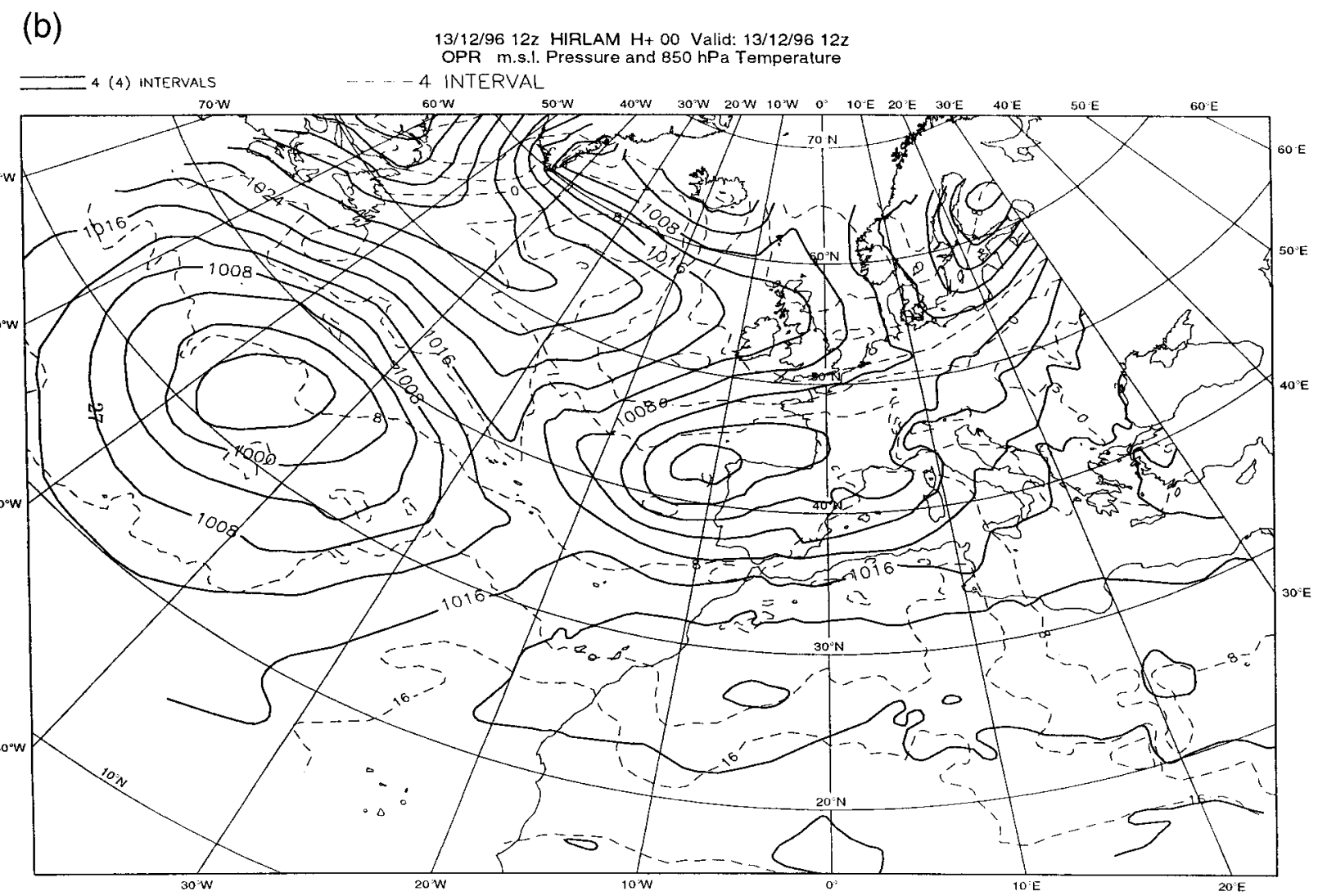

FIg. 3. (Continued)

is five times larger and PW deviates more and more from a mean value the longer the time period.

In order to compare PW values derived from GPS data with the other two techniques (radiosonde and HIRLAM) we first transformed the ellipsoidal GPS heights (WGS84 ellipsoid) to sea level heights using the OSU91A geoid model (Rapp et al. 1991). In the area of interest the geoid undulation (i.e., the height of the geoid above the ellipsoid) amounts to about $50 \mathrm{~m}$. This value we subtracted from the ellipsoidal heights.

\section{b. Radiosonde data}

Radiosonde balloons were launched twice a day (at approximately 0000 and 1200 UTC) from the MadridBarajas airport. The balloons, which are operated by the INM, were equipped with Vaisala RS-80s radiosondes with A-humicap humidity sensor (brand names are mentioned for identification purposes only). We obtained zenith hydrostatic and wet delays by integrating the atmospheric profiles sensed by the sonde along its ascending path using (2) and (3), respectively.

Since Barajas is close to the IGNE site (horizontal distance of $\sim 12 \mathrm{~km}$, height difference of $\sim 82 \mathrm{~m}$; see Fig. 1), we have also compared atmospheric delays derived from GPS at IGNE and radiosonde at Barajas by integrating the measurements of the latter from the height of IGNE upward. (However, we should note that significant water vapor gradients can occur even over a $12-\mathrm{km}$ distance, specially during the passage of a frontal system.) The balloons reach a maximum height above the geoid of approximately $25-30 \mathrm{~km}$. To compare formally GPS and radiosonde delays, one would have to integrate the radiosonde measurements up to the altitudes of the GPS satellites. Since this is not obviously possible, we have used the following procedure to extrapolate the radiosonde data (temperature, dew point temperature and pressure) above the last measurement available and derive radiosonde delays.

- Temperature: We used the same values as in the upper level of the HIRLAM model (see section 4c).

- Dewpoint temperature: We assigned it low values to get a zero wet-pressure value-that is, we assumed that there will not be any significant amount of water vapor at, and above, these high altitudes (i.e., $30 \mathrm{~km}$ upward), which is a realistic assumption (Bertin et al. 1996.)

- Pressure: We used a constant temperature (isothermal) condition from an altitude of about $12 \mathrm{~km}$ upward throughout the stratosphere, which is a quite realistic approximation. The equation of hydrostatic equilibrium $d P / P=-(M g / R T) d h$ can be readily integrated because $T$ is constant throughout this region. 
(c)

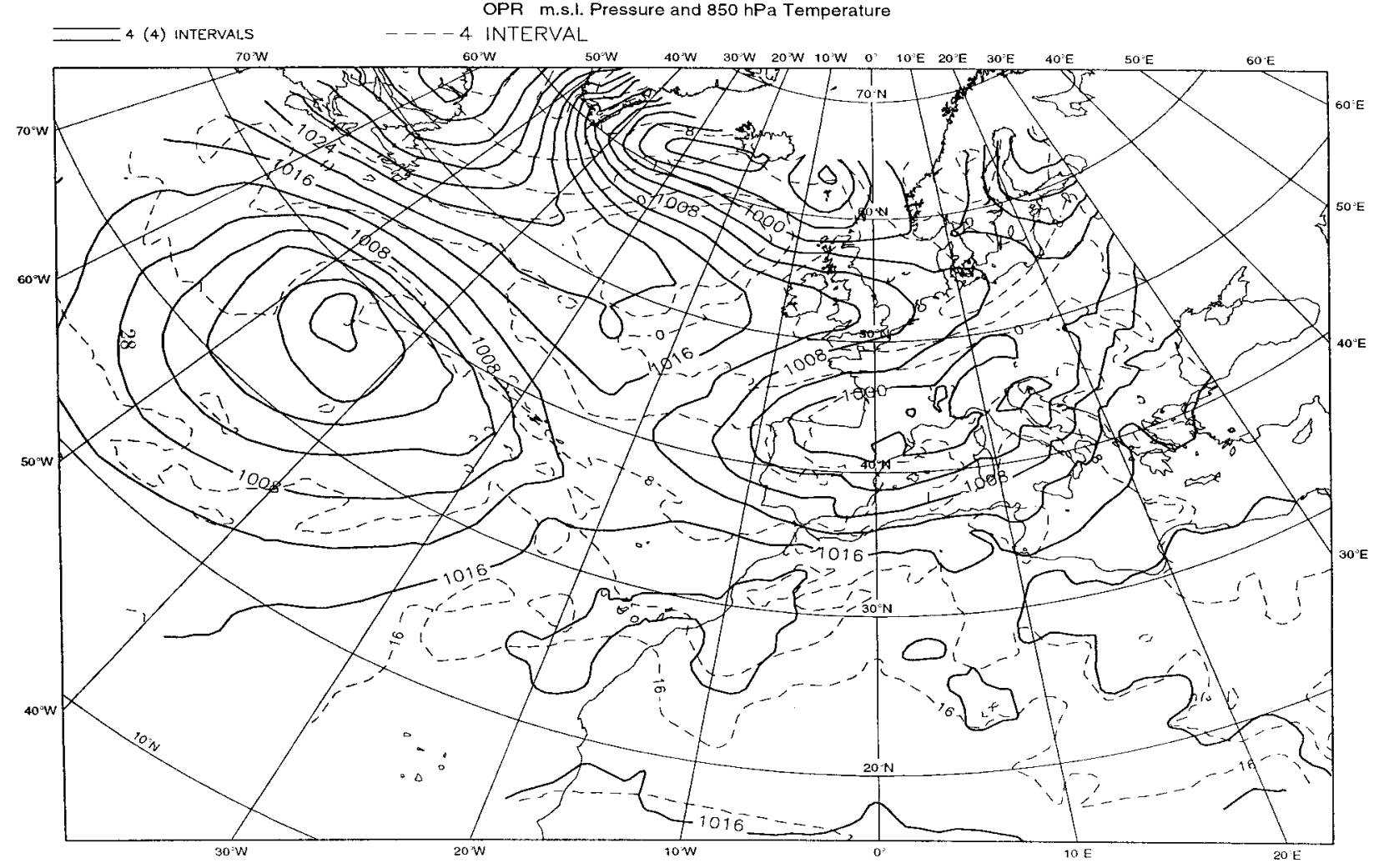

FIG. 3. (Continued)

This isothermal condition leads to the equation for pressure $P$ at altitudes $h$ above $12 \mathrm{~km}$ (the approximate altitude of the tropopause $h_{\mathrm{TP}}$ ),

$$
P=P_{\mathrm{TP}} \exp \left[\frac{-M g\left(h-h_{\mathrm{TP}}\right)}{R T_{\mathrm{TP}}}\right],
$$

where $P_{\mathrm{TP}}$ is the pressure at the tropopause, $M$ is the molar mass of the air, $g$ is the effective acceleration of gravity in the stratosphere (assumed constant), $R$ is the universal gas constant, and $T_{\mathrm{TP}}$ is the temperature at the tropopause (Bertin et al. 1996). Since from an altitude of about $12 \mathrm{~km}$ pressure decreases exponentially with altitude, we fitted the radiosonde pressure data obtained from the tropopause upwards (we took $h_{\mathrm{TP}}$ as $12 \mathrm{~km}$ ) with an exponential law, from which we obtained the lapse rate. The values of $P_{\mathrm{TP}}$ and $T_{\mathrm{TP}}$ in (7) are provided by the soundings. We found an average standard deviation of about $0.6 \mathrm{hPa}$ when fitting the pressure with an exponential function. This same law allowed us to extrapolate the pressure values to higher altitudes. Note that as the pressure is almost zero at about $70 \mathrm{~km}$ and all the functions involved in the delays calculation have pressure in the numerator, it will be enough to extrapolate the height data until about $70 \mathrm{~km}$. We found that the extrapolated "upper atmosphere," that is, the atmosphere from about 30 to about $70 \mathrm{~km}$, contributes an average of $3 \%$ to the zenith total delay. Radisonde zenith wet delays can be converted to PW using (5).

The average PW rms error resulting from considering the contribution of the instrumental errors in the integrating of the radiosonde profiles are about $1 \mathrm{~mm}$. For the Vaisala radiosonde the humidity sensor has a nominal resolution of $1 \%$ and a repeatability (i.e., the standard deviation of differences between two successful calibrations) of $2 \%$, the temperature sensor has a resolution of $0.1 \mathrm{~K}$ and repeatability of $0.2 \mathrm{~K}$, and the pressure sensor has a resolution of $0.1 \mathrm{hPa}$ and repeatability of $0.5 \mathrm{hPa}$.

\section{c. The HIRLAM simulation}

The HIRLAM short-range weather forecasting system is a complete analysis and forecast system over a limited area (Källen 1996). The forecast model is hydrostatic with Eulerian gridpoint numerics. A fourth-order implicit horizontal diffusion is used to prevent the enstrophy accumulate at the smaller scales. The physics contains a parameterization for solar and longwave radiations and for simple surface processes, providing the lower boundary conditions to the first-order turbulence scheme type Louis. In the cloud parameterization, the 
a

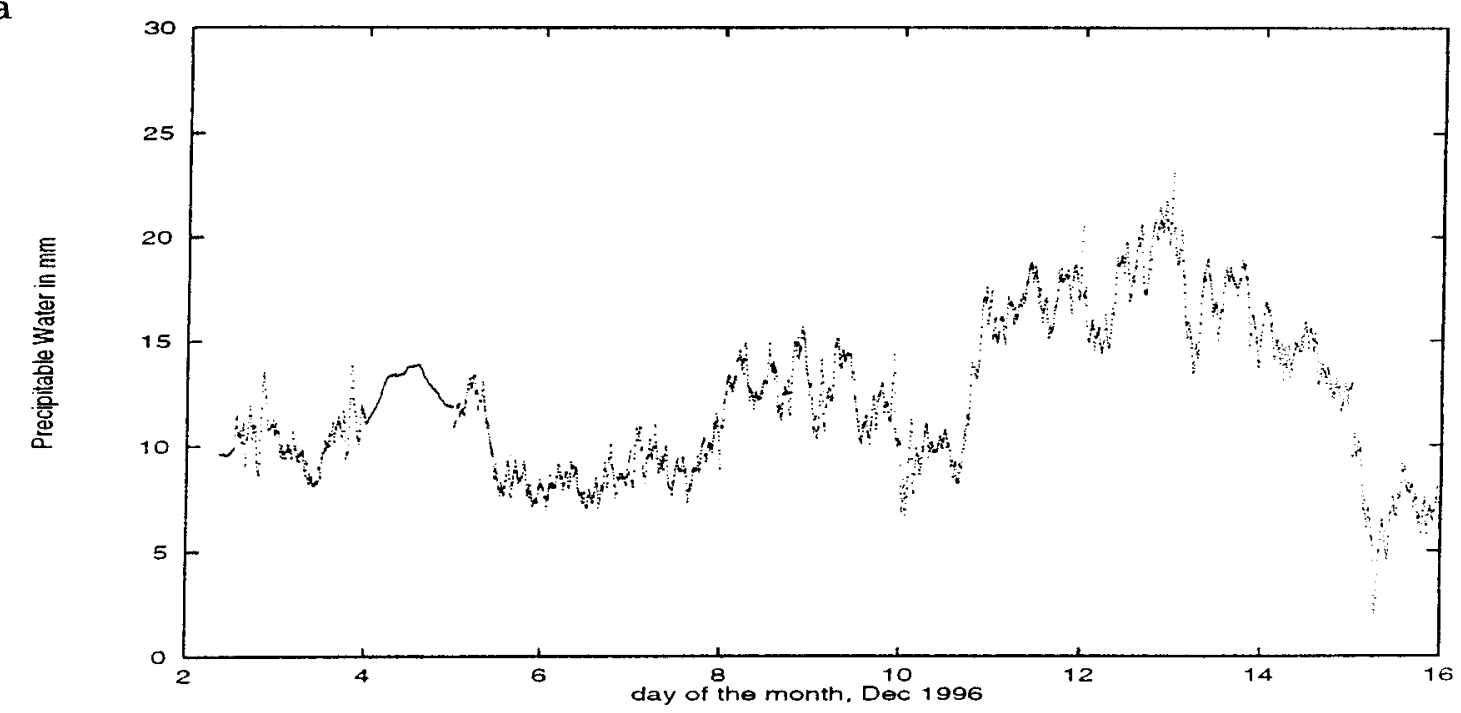

b

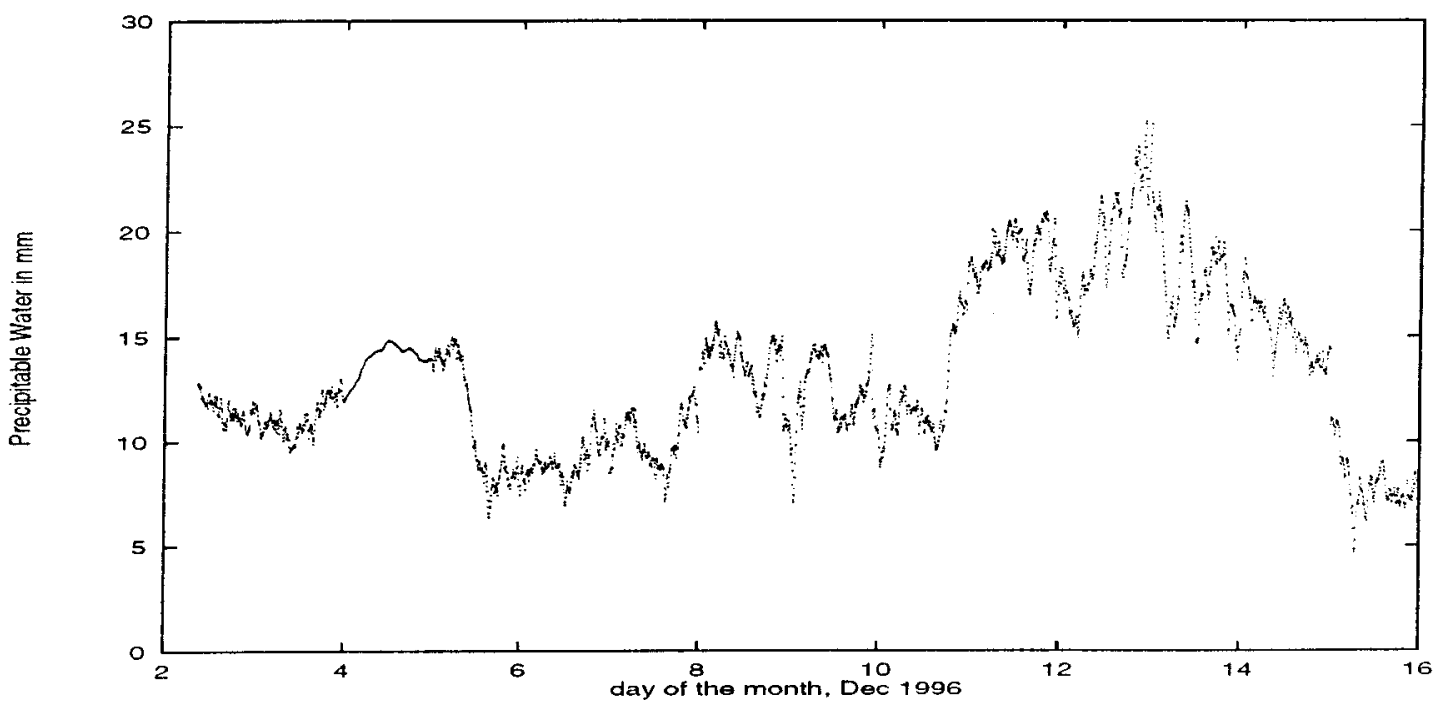

FIG. 4. GPS-derived precipitable water as a function of time for, from top to bottom, (a) Escorial, (b) IGNE, (c) Robledo, (d) Valdemorillo, and (e) Villafranca.

large-scale convection is a Kuo type with a specific treatment of microphysical processes.

At the INM, the HIRLAM system is run at two different horizontal resolutions, $0.5^{\circ}$ latitude by $0.5^{\circ}$ longitude [operational low-resolution run (OPR)], and $0.2^{\circ}$ latitude by $0.2^{\circ}$ longitude [high-resolution run (HIR)], both with the same $31 p$-sigma, hybrid levels, and vertical resolution. The OPR model domain covers the area between $15.5^{\circ}$ and $65.0^{\circ} \mathrm{N}$ and between $-66.5^{\circ}$ and $30.0^{\circ} \mathrm{E}$. Global forecasts from the European Centre for Medium-Range Forecasts (ECMWF) are used as boundary conditions to the OPR model. HIR, one-way nested into the OPR, has been specially designed to cover the Iberia Peninsula. OPR simultaneous fields provide the lateral boundaries to HIR. The topography of Spain, due to its complexity, is much better represented in the HIR than in the OPR.
The HIRLAM model has a 6-h data assimilation cycle. It is based on a limited-area version of the old ECMWF 3D optimum interpolation (OI) scheme for the analysis of the upper air fields (Lönnberg 1987). It is multivariate in the mass and wind fields and univariate in the relative humidity. A short-range, first-guess forecast $(6 \mathrm{~h})$ is corrected by observations from a 3 -h period spanning the nominal analysis time. Single-level data from the surface land stations, ships, buoys as well as from aircraft are used. Also, winds from geostationary satellites are introduced into the analysis. Multilevel observation reports processed include information from radiosondes and pilot balloons (e.g., TEMP and PILOT). A later step of normal modes initialization is performed after the analysis. OPR and HIR runs have their separated assimilation cycles.

At the INM, 6-h temporal series for the HIRLAM/A 


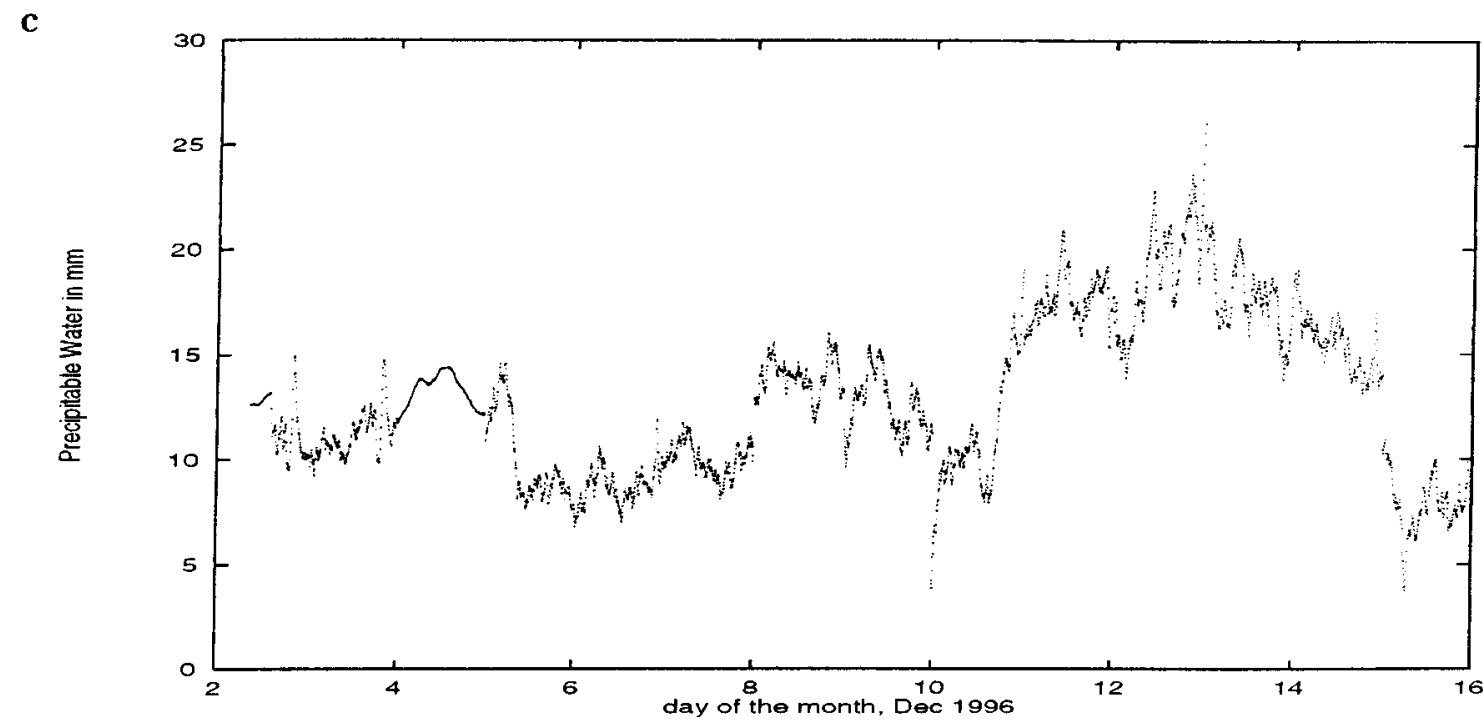

d

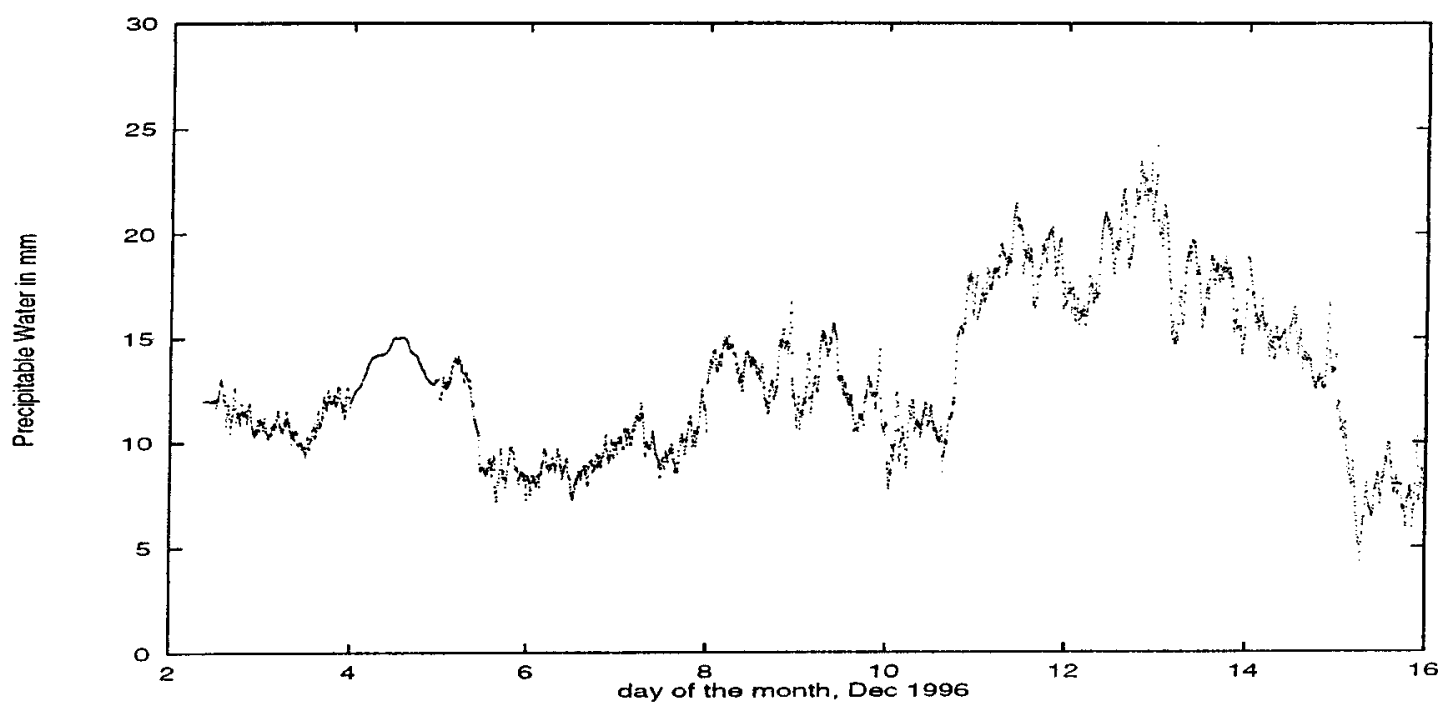

FIG. 4. (Continued)

model and the 3-h interval for the HIRLAM/F are the only available simulations in an operational way. Accordingly, we have used the 0000, 0600, 1200, and 1800 UTC HIR analysis (HIRLAM/A) and the 0000 UTC HIR forecasts at regular intervals from 3 to $24 \mathrm{~h}$ (HIRLAM/F) to simulate HIRLAM precipitable water. The data for this analysis and forecast come from the HIRLAM archive at the INM. Since the shortest GPS baseline is about $5 \mathrm{~km}$ and the HIRLAM higher grid resolution is about $20 \mathrm{~km}$, we have interpolated, both horizontally and vertically, the HIR model variables to the locations of the GPS sites before estimating PW. For this, we have used the same operator used by the HIRLAM model to interpolate the boundary condition fields (Källen 1996). Bilinear interpolation from the four closest gridpoint values is used in the horizontal. To move the whole model profile from the model topography to the height of each GPS station, the vertical interpolation is carried out by using tension splines but with emphasis on preserving the stability properties inside the planetary boundary layer. To interpolate vertically the pressure field from the model topography to the height of each GPS station, we have integrated the hydrostatic equation from the HIRLAM surface level to the height of the GPS site using a virtual temperature profile expressed as a linear function of the logarithm of pressure in the vicinity of the GPS level. In case that the GPS station is below the HIRLAM surface level, the virtual temperature is obtained by extrapolation from the three lowest HIRLAM levels; otherwise, the temperature profile is obtained by interpolation from the three closest HIRLAM levels to the GPS surface level. This linear virtual temperature profile is obtained by regression from the three selected HIRLAM temperatures. 
e

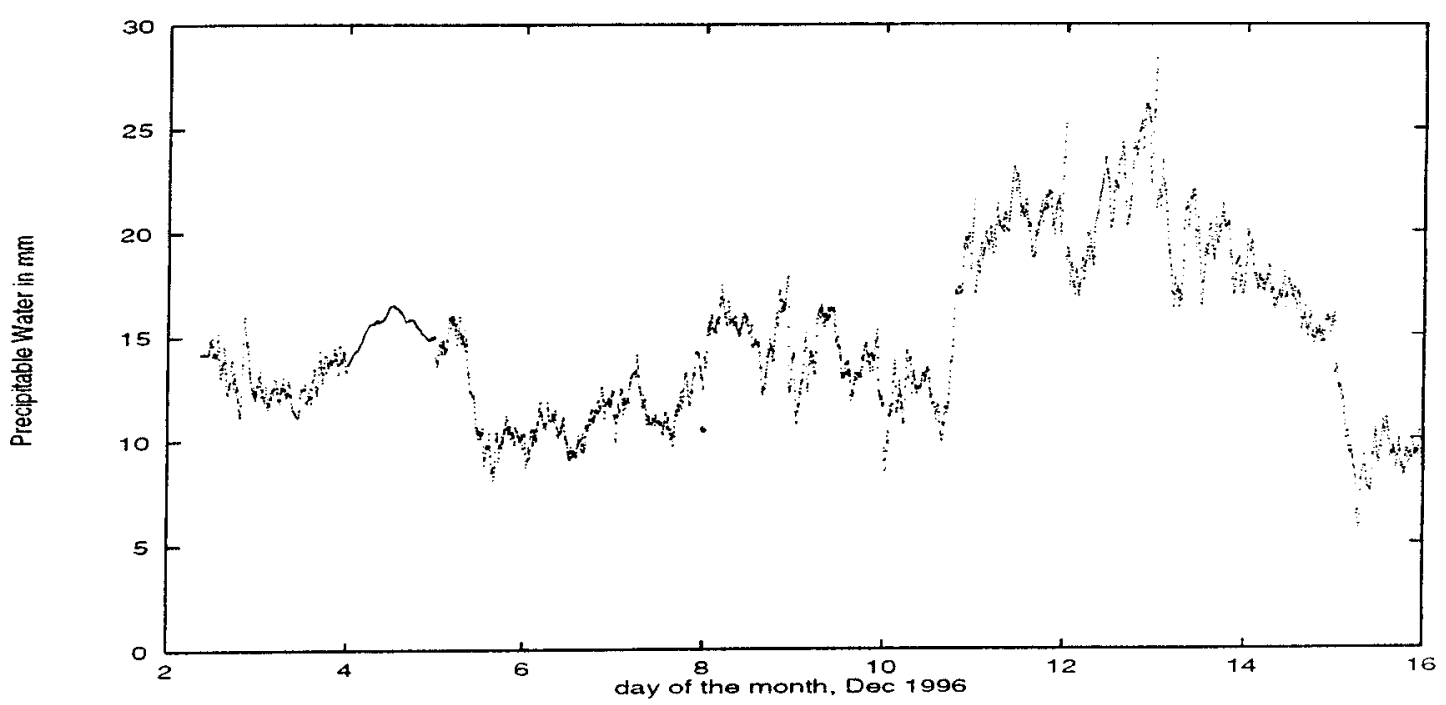

FIG. 4. (Continued)

The PW was calculated at every GPS station by integrating the specific humidity in the vertical, $\mathrm{PW}=$ $\int d P\left(1 / \rho_{v}\right)(q / g)$, where $q$ is the specific humidity, $P$ the pressure, $g$ the acceleration of gravity, and $\rho_{v}$ the density of water. The scores of verification against observations of the HIRLAM products at the INM have been used to estimate the error of the calculated PW. The resulting error associated to the PW HIRLAM model varies from 1.4 to $2.1 \mathrm{~mm}$.

In addition, we used a second method to check for the HIRLAM-derived PW values. We used the temperature, pressure, and humidity profiles of HIRLAM to generate refractivity profiles. The integration of these profiles along the zenith direction gives us the zenith wet delays after applying (3). These simulated zenith delays can be converted to PW using (5). The PW values obtained by the HIRLAM model (from humidity and pressure profiles) are consistent with the PW values calculated from the integration of the profiles of the vertical refractivity of HIRLAM. We found an average PW bias of $0.5 \mathrm{~mm}$ ( $\mathrm{rms}$ of $0.2 \mathrm{~mm}$ ) between both techniques. This good agreement confirms the validity of the value of 0.15 used for $\Pi$ in (6) to infer PW from estimates of zenith wet delays with GPS.

\section{Results and discussion}

We have used estimates of PW to study the ability of GPS to describe the evolution of a frontal system that crossed our local network. These PW estimates have an accuracy of $1 \mathrm{~mm}$ and can provide information on certain features associated to the small spatial and short temporal scales of variation of atmospheric water vapor. Comparable PW accuracies have been obtained in previous studies (e.g., Rocken et al. 1995; Tregoning et al. 1998). The frontal passage selected corresponds to the time period of 12-14 December, which is associated with the largest PW values. Figure 5 shows the GPSderived estimates of PW for two of the sites. We have selected Robledo and Escorial as the best-suited site pair to study the passage of the front because they are the two westermost sites of our network and, in consequence, the first ones to detect any noticeable change in water vapor. (The horizonal distance between Robledo and Escorial is $20 \mathrm{~km}$.) A distinctive element of Fig. 5 is that the PW values at Robledo are larger than those at Escorial. This is mostly due, as explained above, to an inverse dependence of the water vapor content with the altitude of the site. Although both series have

TABLE 1. Mean and rms PW for the entire 15-day period and during the two front passages at all GPS stations.

\begin{tabular}{|c|c|c|c|c|c|c|c|}
\hline \multirow[b]{2}{*}{ Station } & \multirow[b]{2}{*}{ Height (m) } & \multicolumn{2}{|c|}{ PW 2-15 Dec } & \multicolumn{2}{|c|}{ PW 4-6 Dec } & \multicolumn{2}{|c|}{ PW 12-14 Dec } \\
\hline & & Mean $(\mathrm{mm})$ & rms (mm) & Mean (mm) & rms (mm) & Mean (mm) & $\mathrm{rms}(\mathrm{mm})$ \\
\hline Escorial & 1026 & 12.2 & 3.6 & 11.3 & 2.1 & 17.5 & 2.0 \\
\hline IGNE & 715 & 13.2 & 3.9 & 12.4 & 2.5 & 18.7 & 2.4 \\
\hline Robledo & 777 & 12.9 & 3.7 & 11.6 & 2.3 & 18.4 & 2.2 \\
\hline Valdemorillo & 794 & 13.1 & 3.7 & 12.2 & 2.3 & 18.5 & 2.2 \\
\hline Villafranca & 596 & 14.7 & 3.9 & 13.7 & 2.4 & 20.5 & 2.5 \\
\hline
\end{tabular}




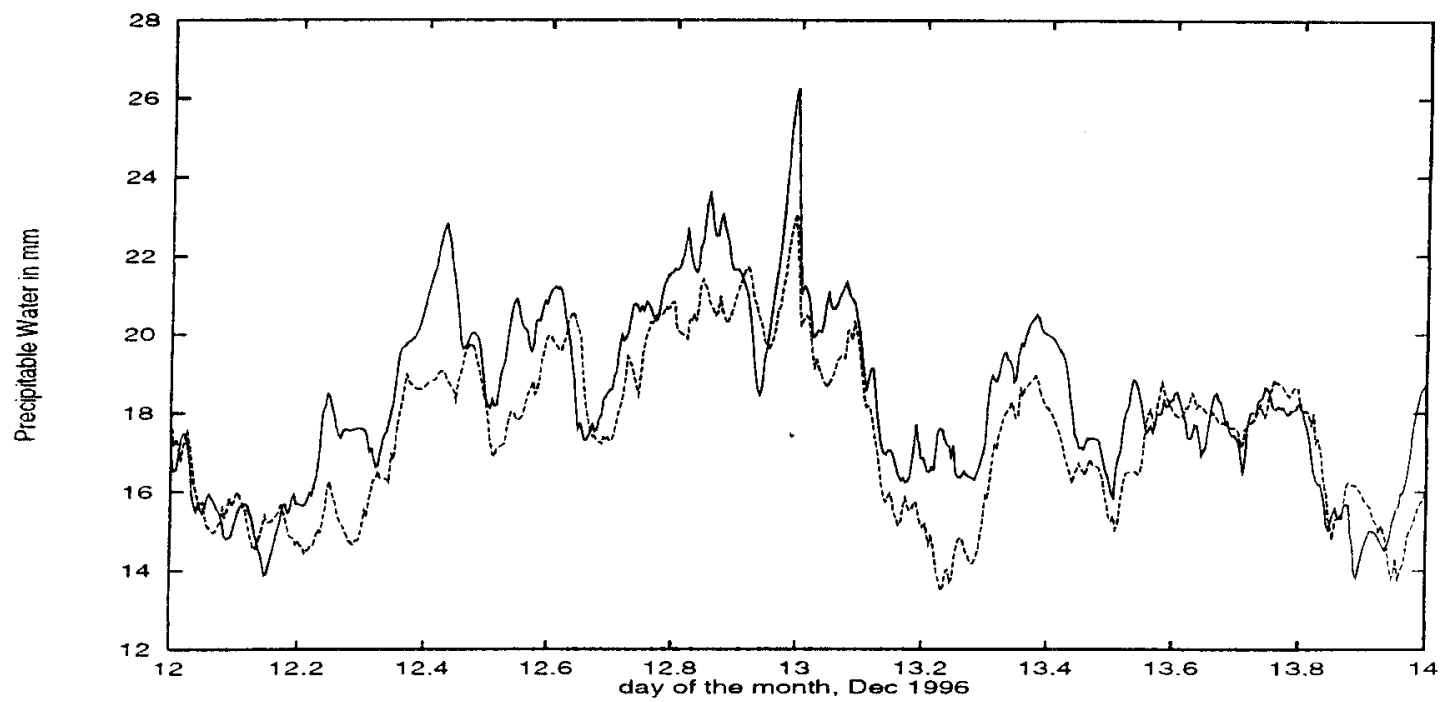

FIG. 5. The 30-min-averaged GPS-derived precipitable water as a function of time at Robledo (continuous line) and Escorial (dashed line) during the passage of a second frontal system in 12-14 Dec.

similar trends, differences between them can be observed. For example, the PW time series present a relative time shift of about 40 min at around 12 December at $14 \mathrm{~h}$, the time series of Robledo leading that of Escorial. This can be interpreted by the air masses with large content of water vapor reaching Robledo earlier than Escorial. The predominant southwesterly winds associated with the front passage (see Fig. 3) bring the air masses rich in water vapor first to Robledo. This example illustrates that relatively short temporal variations of PW over small spatial scales can be accurately determined using GPS.

We will next compare these PW estimates obtained with GPS data (hereafter PW estimates) with the ones calculated using the HIRLAM/A model (hereafter PW modeled) and the radiosonde data. The intercomparison of PW using three different methods is useful to assess their differences and to validate future parameterizations of NWP models. The ability of HIRLAM to simulate topographically induced effects is limited by its spatial resolution, especially in complex terrain. As it was mentioned in the previous section, the HIRLAM lowestresolution model, OPR, was used to drive the largescale flow in the high-resolution HIRLAM runs. For the comparison between PW estimates and PW modeled we will only use the high-resolution model.

Figure 6 shows PW estimates of GPS, HIRLAM/A, and radiosonde for the 15-day period at the IGNE site. The GPS estimates are average values over 30-min periods. (This filtering of the high-frequency component of PW has been performed solely for clarity.) All three datasets agree with each other to a few-millimeter level. However, radiosonde estimates appear systematically lower than the PW obtained with the other two methods. For example, the bias between PW estimates from GPS and radiosondes is $1 \mathrm{~mm}$, with radiosondes lower than
GPS, and the rms difference is $1.6 \mathrm{~mm}$. This rms difference falls within the expected PW error of the combined GPS and radiosonde errors.

The HIRLAM/A model simulates PW during periods of high amount of precipitable water (between 11 and 13 December) reasonably well when compared to GPS PW estimates. The two PW maxima, which occurred at 1200 UTC on 4 December, and at 0000 UTC on 13 December, are associated to the two rainy intervals. The PW-modeled values and the PW estimates are comparable during the precipitation periods, that is, at around 1200 UTC on 4 December and 0000 UTC on 13 December. A strong decrease in total atmospheric moisture occurs shortly after the frontal passage (5 and 15 December). The HIRLAM model does not drop the total water vapor amount so sharply. Rather, it seems to slightly overestimate this low-level moisture conditions with respect to what it is observed with the GPS data. Thus, HIRLAM seems to perform quite well compared to GPS if the PW does not change too rapidly. Indeed, the bias between PW estimates and PW modeled for the entire experiment is $0.2 \mathrm{~mm}$, with GPS lower than HIRLAM. The rms difference is $2.1 \mathrm{~mm}$ and is in agreement with the expected error derived from the standard deviations of GPS and HIRLAM.

The humidity profiles from which the PW modeled are obtained are largely influenced by the relative humidity measured by the radiosondes and assimilated into the HIRLAM model. On the other hand, the relative weight carried by radiosonde measurements on relative humidity at the surface is smaller because the number of sites from which radiosondes are launched in the Iberia Peninsula is, of course, considerably smaller than the volume of surface observations that are assimilated into HIRLAM. Also, the (temporal) sparseness of the radiosonde launches, typically once every $12 \mathrm{~h}$, con- 


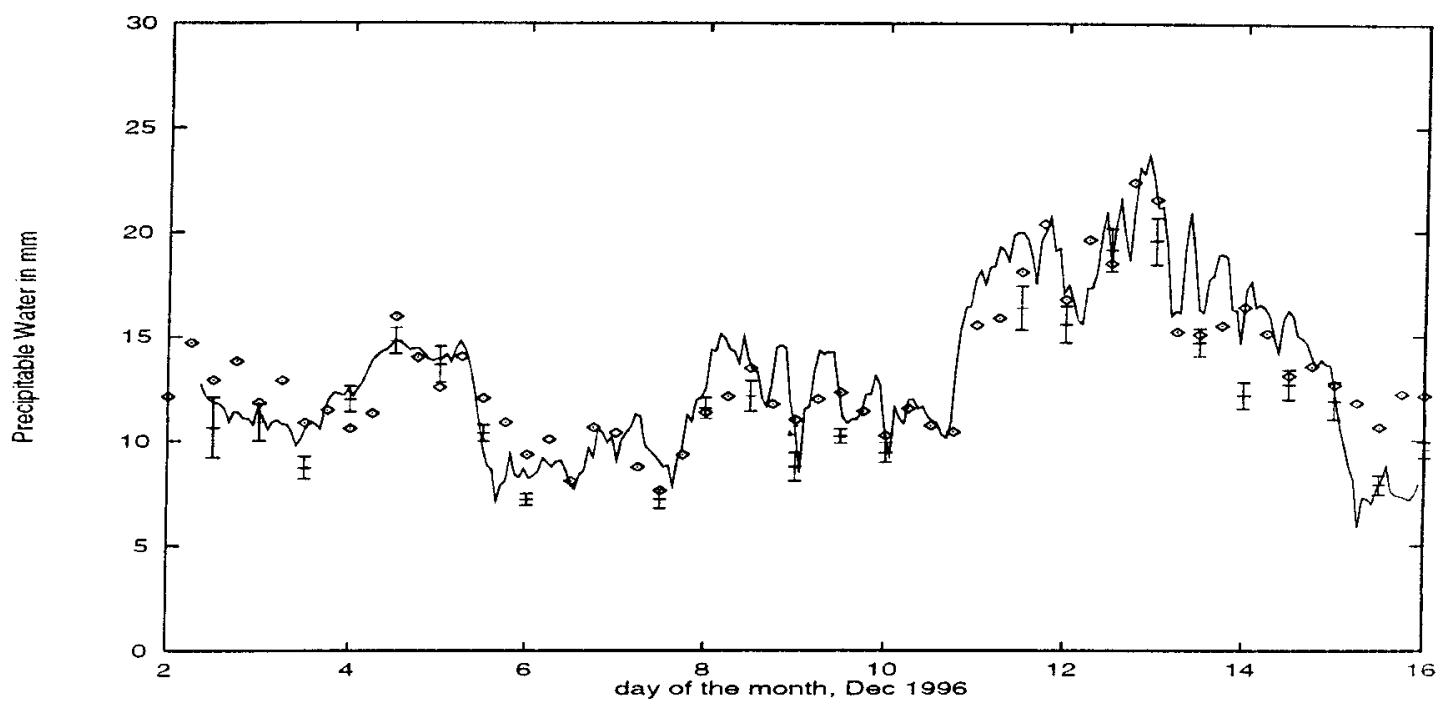

FIG. 6. Estimates of PW from GPS measurements (continuous line) from HIRLAM calculations (diamond) and from integrated radiosonde profiles (stripe with error bars) vertically integrated at IGNE site, as a function of time. The standard deviations of the PW estimates are about $1 \mathrm{~mm}$ (see text) and have not been plotted for clarity. The uncertainties on the radiosonde PW estimates due to the meteorological sensors are shown with their error bars. The HIRLAM PW uncertainties are about $1.7 \mathrm{~mm}$ and are not shown.

tributes to sometimes worsen the PW modeled, which are calculated every $6 \mathrm{~h}$. Fortunately, the Barajas radiosonde site is near one of the GPS stations of this study, which gives us some confidence on the PW calculated from HIRLAM/A profiles.

The PW values retrieved from the radiosonde profiles are lower than the PW calculated using the HIRLAM model (average bias of $1.2 \mathrm{~mm}$ ). However, the rms value of $1.3 \mathrm{~mm}$ shows that the precision of the comparison is at the same level as the standard deviation of both techniques, though they are not totally independent. The algorithm used in the OI analysis filters the observation increment (observation departure from first guess) according to the assumed data to first-guess error ratio. The comparison of calculated PW by using HIRLAM/A and radiosonde atmospheric profiles has been included to show the analysis filter performance.

Table 2 summarizes the site-by-site comparison between PW estimates and PW modeled for the entire experiment. The PW rms value of $2 \mathrm{~mm}$ is in agreement with the standard deviation of each technique and indicates the level of precision expected for future studies in which GPS data will be assimilated in NWP models. Figure 7 compares PW estimates and PW modeled for

TABLE 2. PW-modeled and PW estimates bias and rms for the entire period of the experiment.

\begin{tabular}{lcc}
\hline \multicolumn{1}{c}{ Station } & PW bias $(\mathrm{mm})$ & PW rms $(\mathrm{mm})$ \\
\hline Escorial & -0.7 & 2.0 \\
IGNE & 0.2 & 2.1 \\
Robledo & -0.4 & 2.2 \\
Valdemorillo & -0.4 & 1.9 \\
Villafranca & -0.9 & 2.0 \\
\hline
\end{tabular}

all the GPS sites and the entire campaign. The HIRLAM model reproduces reasonably well the PW measurements around values of about $15 \mathrm{~mm}$. However, below this value there is a tendency for the numerical model values of PW to be higher than the PW estimates. In contrast, the PW-calculated values are lower than the PW estimates for values higher than $15 \mathrm{~mm}$. A straightline fit to this data yields a slope of $0.69 \pm 0.03$, and the $\chi^{2}$ (per degree of freedom) is 3.1.

We also analyzed the PW values obtained with the HIRLAM/F in order to assess the ability of the NWP model to forecast the precipitable water. Figure 8 shows GPS-derived estimates of PW at Robledo during the passage of the second front. The figure also shows the 6-hourly HIRLAM/A PW and the 3-hourly HIRLAM/F values. Unfortunately, it was only possible to obtain values of the PW calculated by HIRLAM/F every $3 \mathrm{~h}$ since these were the only available simulations in an operational way at the INM. For the HIRLAM/F results, and comparing with the HIRLAM/A, the rms increases with the forecast range up to $3 \mathrm{~mm}$ in $24 \mathrm{~h}$. A similar feature is found for the bias $(-1.2 \mathrm{~mm})$. An underestimation of the PW modeled is found when comparing to PW estimates from GPS. As it was expected, the analysis at 0000 and 1200 UTC, which have made use of radiosonde data, produces a $\mathrm{PW}$ value very close to PW estimates by GPS.

\section{Conclusions}

We have studied the spatial distribution and the temporal evolution of atmospheric water vapor in terms of precipitable water (PW) using GPS. The GPS data used 


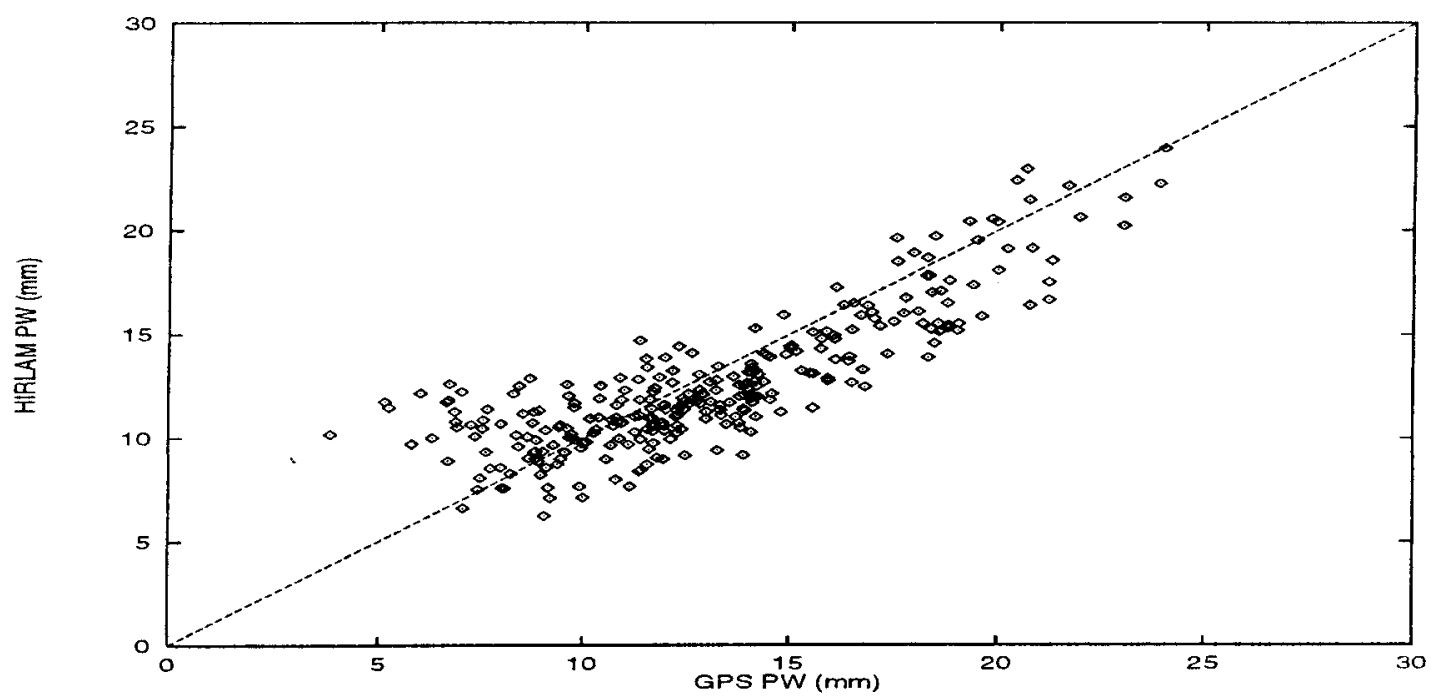

FIG. 7. Comparison of PW estimates against PW modeled for all the network and for all the campaign. The dashed line shows the results of perfect correlation.

in this experiment were acquired in 2-15 December, 1996, in the Madrid Sierra, Spain. We operated a total of five GPS stations that spanned a maximum horizontal distance of $50 \mathrm{~km}$. The atmospheric flow during the time of the experiment was mainly driven by synoptic-scale disturbances. Two frontal systems both associated to large values of PW crossed over the network on 4-6 and 12-14 December, respectively. The HIRLAM numerical weather prediction (NWP) model simulates the PW for this region and time period. The radiosonde data from a nearby site is used to estimate PW during this time period. We have carried out a comparison of the PW obtained using all three methods.

The PW estimates derived from GPS every $30 \mathrm{~min}$ and the PW values obtained from the 6-hourly HIRLAM analysis agree with each other to within $2-\mathrm{mm}$ rootmean-square (rms). This rms value is consistent with the standard deviation of each technique. Hence, to improve the products derived from a numerical weather model such as HIRLAM by assimilating PW in real time the accuracy of these estimates should be of a millimeter level, provided that the meteorological conditions are similar to those encountered in the Madrid Sierra. GPSderived and radiosonde-derived PW estimates agree with each other to within 1.6-mm rms. The radiosonde PW estimates are generally lower than those obtained using GPS and HIRLAM.

In addition, we have used HIRLAM in its forecast

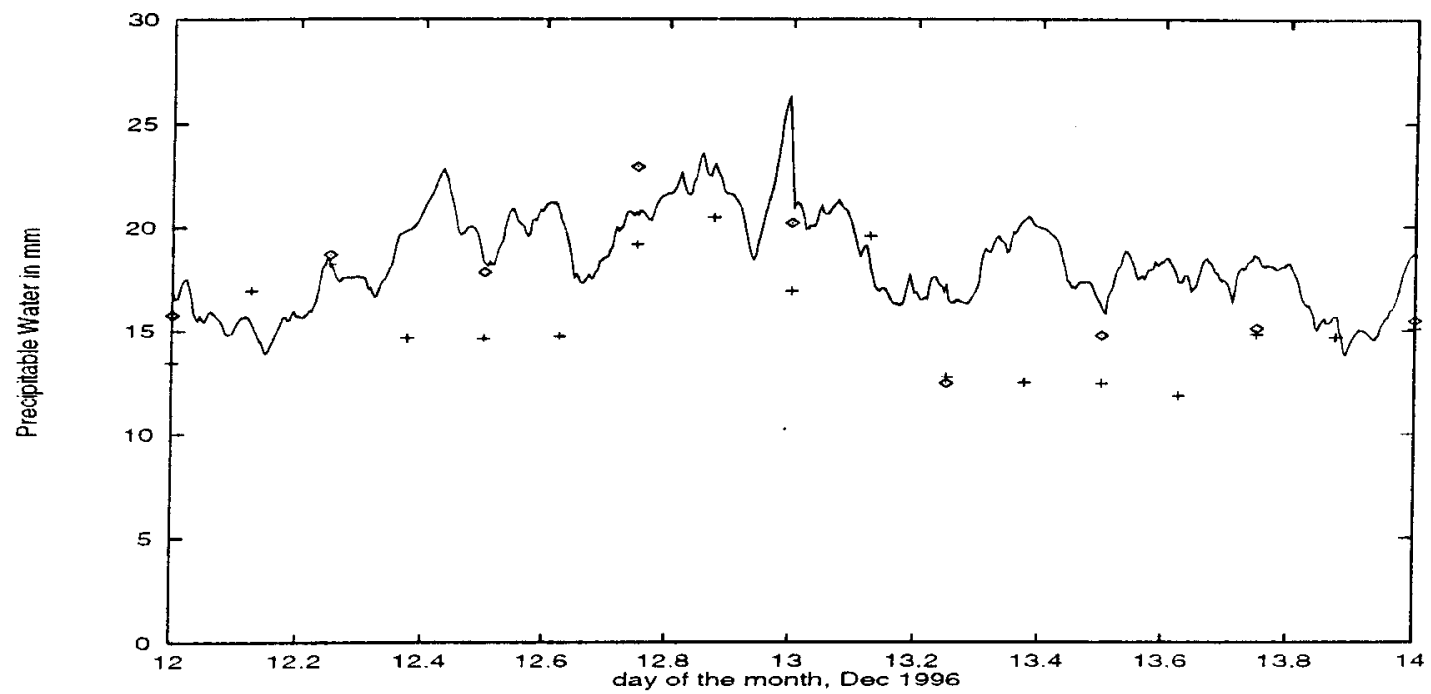

FIG. 8. The Robledo station PW estimates (continuous line) vs PW modeled with the HIRLAM/A (diamond) and HIRLAM/F (cross). 
mode (HIRLAM/F) to extrapolate PW from a given period to a maximum time prediction of $24 \mathrm{~h}$ at regular intervals of $3 \mathrm{~h}$. We have found that the bias and the rms between the PW estimates derived from GPS and the HIRLAM/F predictions increase as the extrapolation time becomes larger. For example, the PW bias between both techniques is $-1.2 \mathrm{~mm}$ and the rms is $3 \mathrm{~mm}$ for a 24-h prediction.

The good PW agreement found among all three methods (GPS, HIRLAM, and radiosondes) is very encouraging for the possible use of GPS atmospheric products in NWP models in the near future. These are promising results since the disparity in the prognostic skill for precipitation is a consequence of the formation of precipitation on scales essentially smaller than those resolved by present-day global models and the lack of mesoscale data with which to initialize regional finemesh models. The availability of such measurements would potentially be useful for studying the distribution of PW on phenomena of smaller spatial scales. The high rate of the GPS data retrievals suggests the assimilation of PW into NWP models in a four-dimensional variational context.

Acknowledgments. We thank CalTech/JPL for providing the GIPSY/OASIS-II package. We are also grateful to Arthur Niell for helpful conversations. L. Cucurull would like to thank F. Vandenberghe and M. Pondeca for valuable discussions on NWP models. Figure 1 was prepared using GMT version 3.0 by Wessel and Smith. The Spanish IGN loaned and operated the GPS receivers. This work was supported by Spanish Climate CICYT Grant CLI95-1781, EC Grant WAVEFRONT PL952007, and MAGIC PL-972065.

\section{REFERENCES}

Bertin, J. J., 1996: Global Positioning System: Theory and Applications. Vol. 1. Progress in Astronautics and Aeronautics, 517546.

Bevis, M., S. Businger, T. A. Herring, C. Rocken, R. A. Anthes, and R. H. Ware, 1992: GPS meteorology: Remote sensing of atmospheric water vapor using the Global Positioning System. $J$. Geophys. Res., 97, 15 787-15 801.

,-- , S. R. Chiswell, T. A. Herring, R. A. Anthes, C. Rocken, and R. H. Ware, 1994: GPS meteorology: Mapping zenith wet delays onto precipitable water. J. Appl. Meteor., 33, 379-386.

Businger, S., and Coauthors, 1996: The promise of GPS in atmospheric monitoring. Bull. Amer. Meteor. Soc., 77, 5-18.

Carlsson, T. R., G. Elgered, and J. M. Johansson, 1996: A quality assessment of the wet path delay estimated from GPS data. Proc. 11th Working Meeting on European VLBI for Geodesy and Astrometry, Research Rep. 177, Onsala Space Observatory, Chalmers University of Technology 89-95.

Chen, G., and T. A. Herring, 1997: Effects of atmospheric azimuthal asymmetry on the analysis of space geodetic data. J. Geophys. Res., 102, 20 489-20 502.

Davis, J. L., T. A. Herring, I. I. Shapiro, A. E. Rogers, and G. Elgered, 1985: Geodesy by radio interferometry: Effects of atmospheric modeling errors on estimates of baseline lengths. Radio Sci., 20, 1593-1607.

Dixon, T. H., and S. Kornreich Wolf, 1990: Some tests of wet tro- pospheric calibration for the CASA Uno Global Positioning System experiment. Geophys. Res. Lett., 17, 203-206.

Duan, J., and Coauthors, 1996: GPS Meteorology: Direct estimation of the absolute value of precipitable water. J. Appl. Meteor., 35, $830-838$.

Elgered, G., J. L. Davis, T. A. Herring, and I. I. Shapiro, 1991: Geodesy by radio interferometry: Water vapor radiometry for estimation of the wet delay. J. Geophys. Res., 96, 6541-6555.

Elósegui, P., A. Rius, J. L. Davis, G. Ruffini, S. J. Keihm, B. Bürki, and L. P. Kruse, 1998: An experiment for estimation of the spatial and temporal variations of water vapor using GPS data. Phys. Chem. Earth, 23, 125-130.

Emardson, T. R., and H. J. P. Derks, 1999: On the relation between the wet delay and the integrated precipitable water vapor in the European atmosphere. Meteor. Appl., 6, 1-12.

—, G. Elgered, and J. M. Johansson, 1998: Three months of continuous monitoring of atmospheric water vapor. J. Geophys. Res., 103, 1807-1820.

Herring, T. A., J. L. Davis, and I. I. Shapiro, 1990: Geodesy by radio interferometry: The application of Kalman filtering to the analysis of very long baseline interferometry data. J. Geophys. Res., 95, 561-581.

Källen, E., Ed., 1996: HIRLAM documentation manual, System 2.5. SMHI, 120 pp. [Available from Erland Källen, SMHI, S-60179 Norrköping, Sweden.]

Kuo, Y.-H., Y.-R. Guo, and E. R. Westwater, 1993: Assimilation of precipitable water into mesoscale numerical model. Mon. Wea. Rev., 121, 1215-1238.

_ X. Xou, and Y.-R. Guo, 1996: Variational assimilation of precipitable water using nonhydrostatic mesoscale adjoint model. Part I: Moisture retrieval and sensitivity experiments. Mon. Wea. Rev., 124, 122-147.

Lönnberg, P., and D. Shaw, 1987: ECMWF data assimilation scientific documentation. Research Manual 1. 3/92, 3d ed. ECMWF Meteorological Bull. M1.5/1, 100 pp. [Available from ECMWF Library, Shinfield Park, Reading, Berkshire RG12 9AX, United Kingdom.]

Niell, A., 1996: Global mapping functions for the atmosphere delay at radio wavelengths. J. Geophys. Res., 101, 3227-3246.

Owens, J. C., 1967: Optical refractive index of air: Dependence on pressure, temperature and composition. Appl. Opt., 6, 51-58.

Rapp, R. H., Y. M. Wang, and N. K. Pavlis, 1991: The Ohio State 1991 geopotential and sea surface topography harmonic coefficient models. Dept. of Geodetic Science and Surveying Rep. 410, The Ohio State University, $100 \mathrm{pp}$. [Available from The Ohio State University, Columbus, OH 43210.]

Rocken, C., R. H. Ware, T. Van Hove, F. S. Solheim, C. Alber, J. Johnson, M. Bevis, and S. Businger, 1993: Sensing atmospheric water vapor with the global positioning system. Geophys. Res. Lett., 20, 2631-2634.

—, T. Van Hove, J. Johnson, F. S. Solheim, R. H. Ware, M. Bevis, and S. R. Chiswell, 1995: GPS/STORM-GPS sensing of atmospheric water vapor for meteorology. J. Atmos. Oceanic Technol., 12, 468-478.

-, , and R. H. Ware, 1997: Near real-time GPS sensing of atmospheric water vapor. Geophys. Res. Lett., 24, 3221-3224.

Ruffini, G., L. P. Kruse, A. Rius, B. Bürki, L. Cucurull, and A. Flores, 1999: Estimation of tropospheric zenith delay gradients over the Madrid area using GPS and WVR data. Geophys. Res. Lett., 26, $447-450$.

Saastamoinen, J., 1972: Atmospheric correction for the troposphere and stratosphere in radio ranging of satellites. The Use of Artificial Satellites for Geodesy, Geophys. Monogr., No. 15, Amer. Geophys. Union, 247-251.

Smith, E. K., and S. Weintraub, 1953: The constants in the equation for atmospheric refractive index at radio frequencies. Proc. IRE, 1035-1037.

Thayer, D. M., 1974: An improved equation for the radio refractive index of air. Radio Sci., 9, 803-807.

Thompson, A. R., J. M. Moran, and G. W. Swenson Jr., 1986: In- 
terferometry and Synthesis in Radio Astronomy. John Wiley and Sons, $534 \mathrm{pp}$.

Tregoning, P., R. Boers, D. O’Brien, and M. Hendy, 1998: Accuracy of absolute precipitable water vapor estimates from GPS observations. J. Geophys. Res., 103, 28 701-28 710.

Ware, R. H., C. Alber, C. Rocken, and F. S. Solheim, 1997: Sensing integrated water vapor along GPS ray paths. Geophys. Res. Lett., 24, 417-420.

Webb, F. H., and J. F. Zumberge, 1993: An introduction to the GIPSYOASIS-II. JPL Publ. D-11088, 300 pp
Yang, X., B. H. Sass, G. Elgered, J. M. Johansson, and T. R. Emardson, 1999: A comparison of the precipitable water vapor estimates by an NWP simulation and GPS observations. J. Appl. Meteor., 38, 941-956.

Yuan, L., R. A. Anthes, R. H. Ware, C. Rocken, W. D. Bonner, M. Bevis, and S. Businger, 1993: Sensing climate change using the Global Positioning System. J. Geophys. Res., 98, 14 925-14 937.

Zou, X., and Y.-H. Kuo, 1996: Rainfall assimilation through an optimal control of initial and boundary conditions in a limited-area mesoscale model. Mon. Wea. Rev., 124, 2859-2882. 